\title{
Protective effects of centrally acting sympathomodulatory drugs on myocardial ischemia induced by sympathetic overactivity in rabbits
}

\section{Catelli ${ }^{1}$, J. Feldman², \\ P. Bousquet ${ }^{2}$ and E. Tibiriçá ${ }^{1}$}

\author{
Correspondence \\ E. Tibiriçá \\ Departamento de Fisiologia \\ e Farmacodinâmica \\ Instituto Oswaldo Cruz, FIOCRUZ \\ Av. Brasil, 4365 \\ 21045-900 Rio de Janeiro, RJ \\ Brasil \\ Fax: +55-21-2590-9490 \\ E-mail: etibi@ioc.fiocruz.br \\ Research supported by FAPERJ \\ (No. E-26/170.120/1999) and CNPq \\ (No. 520287/96-7).
}

Received January 31, 2002

Accepted September 13, 2002

\author{
'Departamento de Fisiologia e Farmacodinâmica, Instituto Oswaldo Cruz, FIOCRUZ, \\ Rio de Janeiro, RJ, Brasil \\ ${ }^{2}$ Laboratoire de Neurobiologie et Pharmacologie Cardiovasculaire, \\ Faculté de Médecine, Université Louis Pasteur, Strasbourg, France
}

\begin{abstract}
It is recognized that an imbalance of the autonomic nervous system is involved in the genesis of ventricular arrhythmia and sudden death during myocardial ischemia. In the present study we investigated the effects of clonidine and rilmenidine, two centrally acting sympathomodulatory drugs, on an experimental model of centrally induced sympathetic hyperactivity in pentobarbital-anesthetized New Zealand albino rabbits of either sex $(2-3 \mathrm{~kg}, \mathrm{~N}=89)$. We also compared the effects of clonidine and rilmenidine with those of propranolol, a $\beta$ blocker, known to induce protective cardiovascular effects in patients with ischemic heart disease. Central sympathetic stimulation was achieved by intracerebroventricular injection of the excitatory amino acid L-glutamate $(10 \mu \mathrm{mol})$, associated with inhibition of nitric oxide synthesis with L-NAME $(40 \mathrm{mg} / \mathrm{kg}$, iv). Glutamate triggered ventricular arrhythmia and persistent ST-segment shifts in the ECG, indicating myocardial ischemia. The intracisternal administration of clonidine $(1 \mu \mathrm{g} / \mathrm{kg})$ and rilmenidine $(30 \mu \mathrm{g} / \mathrm{kg})$ or of a nonhypotensive dose of rilmenidine $(3 \mu \mathrm{g} / \mathrm{kg})$ decreased the incidence of myocardial ischemia $(25,14$ and $25 \%$, respectively, versus $60 \%$ in controls) and reduced the mortality rate from $40 \%$ to $0.0,0.0$ and $12 \%$, respectively. The total number of ventricular premature beats per minute fell from $30 \pm 9$ in the control group to $7 \pm 3,6 \pm 3$ and $2 \pm 2$, respectively. Intravenous administration of clonidine $(10 \mu \mathrm{g} / \mathrm{kg})$, rilmenidine $(300$ $\mu \mathrm{g} / \mathrm{kg})$ or propranolol $(500 \mu \mathrm{g} / \mathrm{kg})$ elicited similar protective effects. We conclude that clonidine and rilmenidine present cardioprotective effects of central origin, which can be reproduced by propranolol, a lipophilic ß-blocking agent.
\end{abstract}

\section{Introduction}

Activation of the central sympathetic nervous system has proved to be a definitive pathophysiological feature in cardiovascular diseases such as primary arterial hyperten-
Key words

- Autonomic nervous system

- Antihypertensive agents

- Antiarrhythmic agents

- Ischemia

- Sudden death sion, heart failure and arrhythmogenesis during myocardial ischemia (1). In fact, experimental and clinical evidence suggests that sudden cardiac death in ischemic patients is mediated, at least in part, by the central nervous system (2-4). Moreover, an imbal- 
ance of the autonomic nervous system, characterized by increased sympathetic activity and reduced vagal activity, results in myocardial electrical instability and promotes the occurrence of ischemic events $(5,6)$. Consequently, the pharmacological modulation of the sympathetic activity with $\beta$ blockers (7) as well as the increase of vagal tonus using muscarinic agonists (3) or cholinesterase inhibitors such as pyridostigmine (8) elicit cardioprotective effects. Sympathetic hyperactivity can also be modulated by drugs acting directly on its site of origin, i.e., the central nervous system. In this context, first generation centrally acting antihypertensive drugs such as clonidine have been used in the treatment of essential arterial hypertension (9). Nevertheless, the antihypertensive effect of this class of drugs was frequently accompanied by important central side effects such as sedation and dry mouth, resulting in a loss of interest in its clinical use (9). In the past two decades, after the existence of a new class of pharmacological receptors was demonstrated, the nonadrenergic specific imidazoline receptors (10), a second generation of clonidine-like drugs was developed. It was also possible to demonstrate a dissociation between the pharmacological mechanisms involved in the hypotensive effect of imidazoline agents (imidazoline receptors in the ventrolateral medulla) (11-13) and the one responsible for their sedative action $\left(\alpha_{2}\right.$-adrenoceptors in the locus coeruleus) $(12,14)$. In fact, clonidine-derived imidazoline drugs such as rilmenidine and moxonidine have proved to be effective for the treatment of mild to moderate arterial hypertension without presenting significant sedative effects (9).

The purpose of the present study was to determine the effects of systemic and central administration of clonidine and rilmenidine on ventricular arrhythmia, myocardial ischemia and mortality induced by central sympathetic stimulation with L-glutamate in $\mathrm{N}^{\omega_{-}}$ nitro-L-arginine methyl ester (L-NAME)- treated and pentobarbital-anesthetized rabbits. We also compared, in the same experimental model, the protective effects of clonidine and rilmenidine with those obtained by systemic administration of propranolol, a ß-blocker known to present beneficial cardiovascular effects in patients with myocardial ischemia $(7,15)$.

\section{Material and Methods}

\section{Animals and hemodynamic measurements}

The investigation conformed to the Guide for the Care and Use of Laboratory Animals published by the US National Institutes of Health (NIH Publication No. 85-23, revised 1996). New Zealand albino rabbits of either sex (2-3 kg, N = 89) were anesthetized with sodium pentobarbital $(40 \mathrm{mg} / \mathrm{kg})$ administered through the marginal vein of the ear; anesthesia was complemented with second intravenous (iv) injection of $5 \mathrm{mg} / \mathrm{kg}$ pentobarbital before the control period (see below). After induction of anesthesia, a tracheotomy was performed and neuromuscular blockade was induced with pancuronium bromide $(1 \mathrm{mg} / \mathrm{kg}, i v)$. The rabbits were ventilated artificially with room air using a small animal ventilator (Model 7025, Biological Research Apparatus, Ugo Basile, Varese, Italy) at a rate of 25 cycles/min and a tidal volume of $10 \mathrm{ml} / \mathrm{kg}$. Rectal temperature was maintained at $37^{\circ} \mathrm{C}$ with a homeothermic blanket system (Harvard Apparatus, Boston, MA, USA). The right femoral vein was catheterized to permit $i v$ injection. The instantaneous arterial pressure was monitored continuously with a Gould P23D transducer through a catheter placed in the abdominal aorta via the right femoral artery. Left ventricular pressures (LVP) were measured with a high fidelity micromanometertipped size 4F catheter (Millar Mikro-tip catheter model SPR-249, Millar Instruments Inc., Houston, TX, USA) placed in the left ventricle via the right carotid artery. Ana- 
logue pressure signals were digitized at a sampling frequency of $1 \mathrm{~Hz}$ and stored in a computer for later processing using data acquisition software for hemodynamic experiments (Heamodyn for Windows, Hugo Sacks Elektronic, March-Hugstetten, Germany). Heart rate (HR), systolic, diastolic and mean arterial pressures (MAP), LVP and the maximal rates of LVP development $\left(+\mathrm{dP}^{\left.-\mathrm{dt}_{\max }\right)}\right.$ and fall $\left(-\mathrm{dP}^{\mathrm{d}} \mathrm{dt}_{\max }\right)$ were measured. Electrocardiograph (ECG) leads were attached to each extremity and lead II ECG was also monitored continuously and data were stored on the hard disk. ECG calibration was performed using a square wave signal of $1-\mathrm{mV}$ amplitude. After completion of the surgical procedures the animals were allowed to equilibrate for 15-30 min or until a stable MAP tracing was obtained (control period).

Premature ventricular complexes occurring during the $30 \mathrm{~min}$ immediately following intracerebroventricular $(i c v)$ L-glutamate injection were recorded. ST-segment shifts of more than $0.1 \mathrm{mV}$ were also recorded and used as semiquantitative indicators of myocardial ischemia.

\section{Intracerebral injections}

The head of the animal was fixed in a stereotaxic frame (Unimécanique, Epinay/ Seine, France) provided with modified ear bars and an attachment for infraorbital fixation. A craniotomy was performed and the dura mater cut to permit stereotaxic drug injections into the left lateral ventricle. Lglutamate $(10 \mu \mathrm{mol})$ was injected in a constant volume of $100 \mu \mathrm{l}$ of saline solution using a Hamilton microliter syringe (Hamilton Bonaduz AG, Bonaduz, Switzerland) at the following stereotaxic coordinates: AP, $-4.5 \mathrm{~mm}$ from the bregma and $\mathrm{L},-7.5$ and $-6.0 \mathrm{~mm}$ below the cranial surface (16). At the end of each experiment, the same volume $(100 \mu \mathrm{l})$ Evans blue dye was injected under the same conditions. The brain was removed post mortem and dissected to determine whether the drugs had diffused properly throughout the ventricular space. Clonidine and rilmenidine were injected intracisternally (ic) in a constant volume of $50 \mu \mathrm{l}$ directly into the cisterna magna.

\section{Experimental protocol}

L-glutamate $(10 \mu \mathrm{mol}, i c v)$ was always injected $1 \mathrm{~h}$ after $i v$ administration of the nitric oxide synthase inhibitor L-NAME (40 $\mathrm{mg} / \mathrm{kg}$ ) and the above mentioned cardiovascular parameters were continuously recorded (including the ECG).

In the control group, ventricular arrhythmia and ECG changes indicating myocardial ischemia were recorded for $30 \mathrm{~min}$ after Lglutamate injection (Figure 1A). In separate pretreated groups of animals, clonidine (1 $\mu \mathrm{g} / \mathrm{kg}$, ic or $10 \mu \mathrm{g} / \mathrm{kg}, i v)$, rilmenidine (30 $\mu \mathrm{g} / \mathrm{kg}$, ic or $300 \mu \mathrm{g} / \mathrm{kg}$, iv) or propranolol $(500 \mu \mathrm{g} / \mathrm{kg}, i v)$ was administered $10 \mathrm{~min}$ before the injection of L-NAME, and cardiac arrhythmia and ECG changes were monitored as above (Figure 1B). In the posttreated groups, clonidine $(1 \mu \mathrm{g} / \mathrm{kg}, i c)$ or

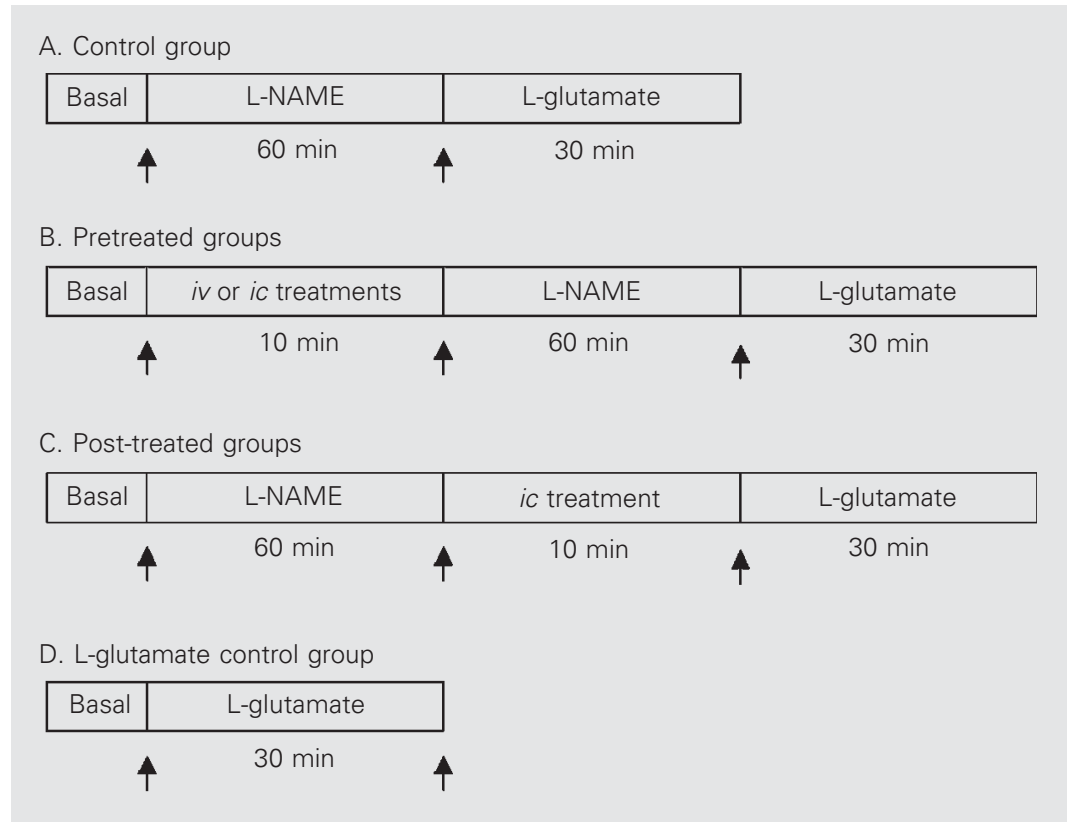

Figure 1. Schematic representation of the experimental protocols. L-NAME, N ${ }^{\omega}$-nitro-Larginine methyl ester; iv, intravenous; ic, intracisternal. 
rilmenidine ( 3 or $30 \mu \mathrm{g} / \mathrm{kg}$, ic) were injected 10 min before L-glutamate and cardiac arrhythmia and ECG changes were monitored for $30 \mathrm{~min}$ (Figure 1C). A separate group of rabbits received only L-glutamate in order to investigate the effects of sympathetic hyperactivity in the absence of nitric oxide synthase inhibition (Figure 1D).

Drugs

Sodium pentobarbital, pancuronium bromide, L-NAME, L-glutamate, propranolol $\mathrm{HCl}$ and clonidine $\mathrm{HCl}$ were purchased from Sigma (St. Louis, MO, USA). Rilmenidine or (2-(N-(dicyclopropylmethyl)amino) oxazoline) was from Tockris Cookson Inc. (Ballwin, MO, USA). Drugs were dissolved in saline $(0.9 \% \mathrm{NaCl})$.

\section{Statistical analysis}

All results are reported as means $\pm \mathrm{SEM}$ for $\mathrm{N}$ experiments. The hemodynamic responses to L-glutamate injections were analyzed by the paired Student $t$-test. Compari- sons between the hemodynamic parameters before and after drug injection within the same experimental groups were made by repeated measures ANOVA followed by the Tukey-Kramer test to determine significant differences. The data of ventricular premature beats $\left(\mathrm{VPB}_{\min }\right)$, which did not have a Gaussian distribution, were transformed to natural $\log$ values and then analyzed by oneway ANOVA. When an overall difference was detected by ANOVA, the Student-Newman-Keuls test was used to determine significant differences. Fisher's exact test was used to compare ST-segment shift and mortality rate data. $\mathrm{P}$ values of less than 0.05 were considered to be statistically significant. All calculations were made by computer-assisted analysis using a commercially available statistical package (Graphpad Instat, Graphpad Software, San Diego, CA, USA).

\section{Results}

\section{Basal cardiovascular parameters}

There were no significant differences in

Table 1. Hemodynamic effects of intravenous (iv) administration of clonidine (CLO), rilmenidine (RIL) or propranolol (PRO) before injection of $\mathrm{N}^{\omega}$-nitro-L-arginine methyl ester (L-NAME, $40 \mathrm{mg} / \mathrm{kg}, i \mathrm{v}$ ) and L-glutamate (GLU, $10 \mu \mathrm{mol}, i c v)$ in pentobarbital-anesthetized rabbits.

\begin{tabular}{lcccc}
\hline Pretreatment & Drugs & MAP $(\mathrm{mmHg})$ & $\mathrm{HR}(\mathrm{bpm})$ & $\mathrm{dP} / \mathrm{dt}$ max $(\mathrm{mmHg} / \mathrm{s})$ \\
\hline Clonidine, $10 \mu \mathrm{g} / \mathrm{kg}, \mathrm{iv}, \mathrm{N}=8$ & Basal & $100 \pm 3$ & $277 \pm 14$ & $2350 \pm 80$ \\
& CLO & $81 \pm 5^{*}$ & $252 \pm 15$ & $1788 \pm 104^{*}$ \\
& L-NAME & $100 \pm 5^{*}$ & $242 \pm 17$ & $2213 \pm 146^{*}$ \\
& GLU & $132 \pm 6^{*}$ & $210 \pm 11^{*}$ & $2500 \pm 141$ \\
Rilmenidine, $300 \mu \mathrm{gg} / \mathrm{kg}, \mathrm{iv}, \mathrm{N}=10$ & Basal & $109 \pm 3$ & $270 \pm 5$ & $2520 \pm 105$ \\
& RIL & $80 \pm 4^{*}$ & $224 \pm 7^{*}$ & $1670 \pm 88^{*}$ \\
& L-NAME & $100 \pm 3^{*}$ & $200 \pm 7^{*}$ & $1990 \pm 87^{*}$ \\
& GLU & $136 \pm 3^{*}$ & $182 \pm 9$ & $2300 \pm 122^{*}$ \\
Propranolol, $500 \mathrm{mg} / \mathrm{kg}, i v, \mathrm{~N}=7$ & Basal & $107 \pm 6$ & $307 \pm 8$ & $2762 \pm 148$ \\
& PRO & $104 \pm 9$ & $230 \pm 4^{*}$ & $1864 \pm 70^{*}$ \\
& L-NAME & $114 \pm 8$ & $261 \pm 6^{*}$ & $1873 \pm 111$ \\
& GLU & $144 \pm 7^{*}$ & $245 \pm 10$ & $2125 \pm 144$ \\
\hline
\end{tabular}

All drugs were injected 10 min before L-NAME; L-glutamate was injected 60 min after L-NAME. MAP, mean arterial pressure; $\mathrm{HR}$, heart rate; $\mathrm{dP} / \mathrm{dt}_{\max }$, maximum rate of rise of left ventricular pressure. Data are reported as means \pm SEM. $\mathrm{N}=$ number of experiments.

${ }^{*} \mathrm{P}<0.05$ vs pre-injection values (Student-Newman-Keuls test) 
mean basal values of MAP between the different experimental groups as shown by $\operatorname{ANOVA}(\mathrm{F}=1.933, \mathrm{P}>0.05, \mathrm{~N}=89)$; basal HR values were slightly but significantly higher in the experimental group treated $i v$ with propranolol $(\mathrm{F}=3.246, \mathrm{P}<0.05$; Tables 1, 2 and 3 ).

\section{Hemodynamic effects of iv injection of L-NAME}

When injected $i v$ in non-pretreated rabbits, L-NAME $(40 \mathrm{mg} / \mathrm{kg})$ induced mild increases in MAP, which were statistically significant in only one experimental group

Table 2. Hemodynamic effects of intracisternal (ic) administration of clonidine (CLO) and rilmenidine (RIL) before injection of $\mathrm{N}^{\omega}$-nitro-L-arginine methyl ester (L-NAME, $40 \mathrm{mg} / \mathrm{kg}, i \mathrm{~V}$ ) and L-glutamate (GLU, $10 \mu \mathrm{mol}$, $i c v)$ in pentobarbital-anesthetized rabbits.

\begin{tabular}{lcccc}
\hline Pretreatment & Drugs & MAP $(\mathrm{mmHg})$ & $\mathrm{HR}(\mathrm{bpm})$ & $\mathrm{dP} / \mathrm{dt}_{\max }(\mathrm{mmHg} / \mathrm{s})$ \\
\hline Clonidine, $1 \mu \mathrm{g} / \mathrm{kg}, i c, \mathrm{~N}=8$ & Basal & $109 \pm 3$ & $248 \pm 8$ & $2669 \pm 85$ \\
& CLO & $82 \pm 4^{*}$ & $229 \pm 10$ & $2115 \pm 123^{*}$ \\
& L-NAME & $88 \pm 9$ & $184 \pm 13^{*}$ & $1938 \pm 174$ \\
& GLU & $131 \pm 10^{*}$ & $184 \pm 2$ & $2582 \pm 172^{*}$ \\
Rilmenidine, $30 \mathrm{mg} / \mathrm{kg}, i c, \mathrm{~N}=7$ & Basal & $102 \pm 4$ & $260 \pm 13$ & $2455 \pm 95$ \\
& RIL & $75 \pm 6^{*}$ & $238 \pm 14$ & $1660 \pm 213^{*}$ \\
& L-NAME & $85 \pm 7$ & $221 \pm 16$ & $1700 \pm 194$ \\
& GLU & $125 \pm 8^{*}$ & $194 \pm 20$ & $2348 \pm 169^{*}$ \\
& & & &
\end{tabular}

CLO and RIL were injected 10 min before L-NAME; L-glutamate was injected 60 min after L-NAME. MAP, mean arterial pressure; $\mathrm{HR}$, heart rate; $\mathrm{dP} / \mathrm{dt}_{\max }$, maximum rate of rise of left ventricular pressure. Data are reported as means \pm SEM. $\mathrm{N}=$ number of experiments.

${ }^{*} \mathrm{P}<0.05$ vs pre-injection values (Student-Newman-Keuls test).

Table 3. Hemodynamic effects of intracisternal (ic) administration of clonidine (CLO) and rilmenidine (RIL) after $\mathrm{N}^{\omega}$-nitro-L-arginine methyl ester (L-NAME, $40 \mathrm{mg} / \mathrm{kg}$, iv) and before L-glutamate (GLU, $10 \mu \mathrm{mol}$, icv) in pentobarbital-anesthetized rabbits.

\begin{tabular}{|c|c|c|c|c|}
\hline Treatment & Drugs & $\mathrm{MAP}(\mathrm{mmHg})$ & HR (bpm) & $\mathrm{dP} / \mathrm{dt}_{\max }(\mathrm{mmHg} / \mathrm{s})$ \\
\hline \multirow[t]{4}{*}{ Clonidine, $1 \mu \mathrm{g} / \mathrm{kg}, i c, N=8$} & Basal & $93 \pm 3$ & $247 \pm 11$ & $1950 \pm 102$ \\
\hline & L-NAME & $116 \pm 4^{*}$ & $233 \pm 16$ & $1875 \pm 150$ \\
\hline & CLO & $85 \pm 6^{*}$ & $211 \pm 18$ & $1412 \pm 212^{*}$ \\
\hline & GLU & $129 \pm 5^{*}$ & $182 \pm 23^{*}$ & $1900 \pm 150$ \\
\hline \multirow[t]{4}{*}{ Rilmenidine, $3 \mu \mathrm{g} / \mathrm{kg}, i c, N=8$} & Basal & $92 \pm 5$ & $244 \pm 8$ & $2422 \pm 120$ \\
\hline & L-NAME & $100 \pm 6$ & $220 \pm 10$ & $2396 \pm 232$ \\
\hline & RIL & $97 \pm 7$ & $214 \pm 16$ & $2324 \pm 265$ \\
\hline & GLU & $122 \pm 6^{*}$ & $202 \pm 12$ & $2775 \pm 167$ \\
\hline \multirow[t]{4}{*}{ Rilmenidine, $30 \mu \mathrm{g} / \mathrm{kg}$, ic, $\mathrm{N}=7$} & Basal & $107 \pm 10$ & $258 \pm 9$ & $2495 \pm 140$ \\
\hline & L-NAME & $119 \pm 4$ & $235 \pm 11$ & $2699 \pm 91$ \\
\hline & RIL & $84 \pm 8^{*}$ & $195 \pm 12^{*}$ & $1933 \pm 185^{*}$ \\
\hline & GLU & $126 \pm 10^{*}$ & $184 \pm 7$ & $2458 \pm 176^{*}$ \\
\hline
\end{tabular}

CLO and RIL were injected 10 min after L-NAME; L-glutamate was injected 5 min after CLO and RIL. MAP, mean arterial pressure; $\mathrm{HR}$, heart rate; $\mathrm{dP} / \mathrm{dt} t_{\text {max }}$, maximum rate of rise of left ventricular pressure. Data are reported as means $\pm \mathrm{SEM}$. $\mathrm{N}=$ number of experiments.

${ }^{*} \mathrm{P}<0.05$ vs pre-injection values (Student-Newman-Keuls test). 
(clonidine $1 \mu \mathrm{g} / \mathrm{kg}$, ic; Table 3). HR and $\mathrm{dP} /$ $\mathrm{dt}_{\max }$ were not modified by L-NAME. In the pretreated groups of animals, L-NAME increased MAP in only two of six groups (clonidine $10 \mu \mathrm{g} / \mathrm{kg}, i v$ and rilmenidine 300 $\mu \mathrm{g} / \mathrm{kg}$, $i v$; Tables 1 and 2). HR fell significantly in two groups (rilmenidine $300 \mu \mathrm{g} / \mathrm{kg}$, $i v$ and clonidine $1 \mu \mathrm{g} / \mathrm{kg}$, ic; Tables 1 and 2 , respectively) and increased in the propranolol-pretreated group (Table 1). L-NAME also induced mild but significant increases in $\mathrm{dP} / \mathrm{dt}_{\max }$ in groups pretreated with clonidine $(10 \mu \mathrm{g} / \mathrm{kg}, i v)$ and rilmenidine $(300 \mu \mathrm{g} / \mathrm{kg} i v$; Table 1).

\section{Cardiovascular effects of the icv injection of L-glutamate in L-NAME-treated rabbits}

L-glutamate (10 $\mu \mathrm{mol}, i c v)$ triggered severe ventricular arrhythmia immediately af-

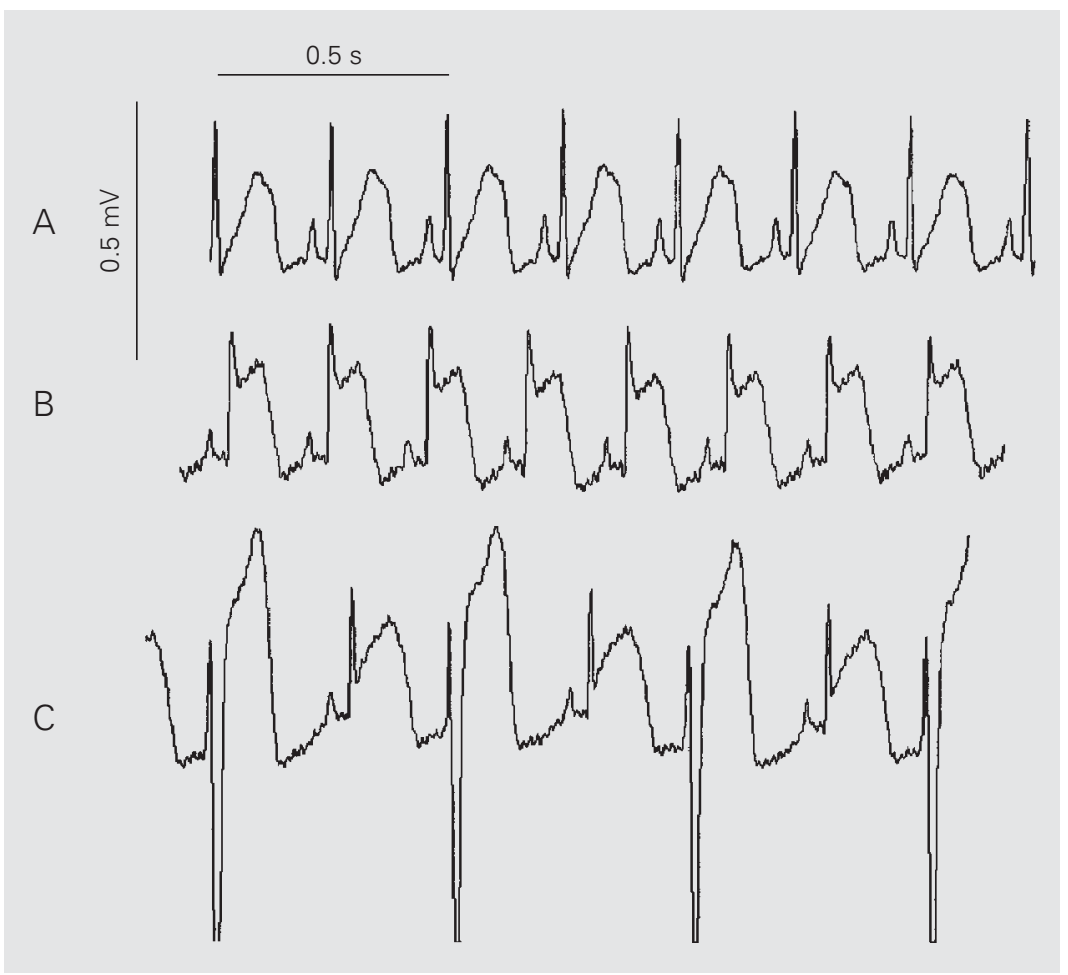

Figure 2. Representative examples of the changes in ECG lead II tracings induced by the central injection of L-glutamate $(10 \mu \mathrm{mol}, i c v)$ in one $\mathrm{N}^{\omega}$-nitro-L-arginine methyl ester ( $\mathrm{L}$ NAME, $40 \mathrm{mg} / \mathrm{kg}, i v)$-treated pentobarbital-anesthetized rabbit. A, Initial ECG. B, ST-segment shift. $C$, Premature ventricular complexes, after injection of L-NAME $(40 \mathrm{mg} / \mathrm{kg}, \mathrm{iv})$ followed by L-glutamate $(10 \mu \mathrm{mol}, \mathrm{icv})$. These typical ECG recordings are representative of those obtained for 18 rabbits (control group). ter $i c v$ injection (Figure 2): total number of $\mathrm{VPB}_{\text {min }}$ was $30 \pm 9(\mathrm{~N}=18)$ during the observation period (30 min). The incidence of ST-segment shift was $61 \%(11 / 18)$ and the mortality rate was $40 \%(7 / 18)$ (Figure 3 ). L-glutamate also induced significant increases in $\mathrm{dP} / \mathrm{dt}_{\max }$ that reached a maximum of $23 \pm 9 \%$ (1898 \pm 241 before and $2245 \pm$ $229 \mathrm{mmHg} / \mathrm{s}$ after L-glutamate administration; $\mathrm{N}=18, \mathrm{P}<0.05)$. The maximum increase in MAP was $31 \pm 7 \%$ (112 \pm 7 before and $143 \pm 4 \mathrm{mmHg}$ after L-glutamate administration; $\mathrm{N}=18, \mathrm{P}<0.05$ ).

Effects of L-glutamate in the absence of the nitric oxide synthase inhibitor

The hemodynamic responses to L-glutamate alone were not significantly different from those of the L-NAME-treated groups (data not shown). The total number of $\mathrm{VPB}_{\text {min }}$ in the 30-min period after L-glutamate injection was only $2 \pm 2$; we did not observe any ST-segment shift on the ECG, and all animals survived until the end of the experiment.

\section{Effects of treatments with clonidine, rilmenidine and propranolol on cardiovascular parameters}

The $i v$ administration of clonidine (10 $\mu \mathrm{g} / \mathrm{kg})$ and rilmenidine $(300 \mu \mathrm{g} / \mathrm{kg})$ before L-NAME (pretreated groups) induced significant hypotensive and negative inotropic effects; only rilmenidine elicited significant bradycardia at the doses used in this study (Table 1). On the other hand, systemic administration of propranolol $(500 \mu \mathrm{g} / \mathrm{kg}, i v)$ elicited significant bradycardia and reduction of $\mathrm{dP} / \mathrm{dt}_{\max }$ which were not accompanied by arterial hypotension (Table 1). The ic administration of a ten times lower dose of clonidine $(1 \mu \mathrm{g} / \mathrm{kg})$ and rilmenidine $(30 \mu \mathrm{g} /$ $\mathrm{kg}$ ) under the same experimental conditions as above also induced significant arterial hypotension and reduction of $\mathrm{dP} / \mathrm{dt}_{\max }$ (Table 
$2)$. When the same doses of clonidine and rilmenidine were injected $60 \mathrm{~min}$ after LNAME (post-treated groups) hypotensive and negative inotropic responses were also observed; only rilmenidine induced a significant reduction in HR (Table 3 ). In contrast, a dose of rilmenidine $(3 \mu \mathrm{g} / \mathrm{kg})$ one hundred times lower than that injected systemically did not induce any significant cardiovascular effect after ic administration (Table 3). The hypertensive response to icv L-glutamate was not modified by the above-mentioned treatments but the increases in $\mathrm{dP} /$ $\mathrm{dt}_{\max }$ were abolished by propranolol and were inconsistently attenuated by systemic or central administration of clonidine and rilmenidine (see Tables 1, 2 and 3).

Effects of intravenous treatments on the frequency of $\mathrm{VPB}_{\min }, \mathrm{ST}$-segment shift and mortality rate

The $i v$ treatment with clonidine $(10 \mu \mathrm{g} /$ $\mathrm{kg})$, rilmenidine $(300 \mu \mathrm{g} / \mathrm{kg})$ and propranolol $(500 \mu \mathrm{g} / \mathrm{kg})$ significantly reduced the total number of $\mathrm{VPB}_{\min }$ from $30 \pm 9$ to $18 \pm 12$, $9 \pm 6$ and 0 , respectively (Figure 3). The incidence of ST-segment shift was also significantly reduced by these treatments. The mortality rate was only $12.5 \%(1 / 8, \mathrm{P}=0.3)$ in the group of animals pretreated with clonidine and all the animals pretreated with rilmenidine $(\mathrm{P}<0.05)$ and propranolol $(\mathrm{P}=$ 0.1 ) survived up to $30 \mathrm{~min}$ after L-glutamate injection.

\section{Effects of intracisternal treatments on the incidence of $\mathrm{VPB}_{\min }$, ST-segment shift and mortality rate}

The ic administration of rilmenidine (30 $\mu \mathrm{g} / \mathrm{kg})$ but not of clonidine $(1 \mu \mathrm{g} / \mathrm{kg}) 10 \mathrm{~min}$ before L-NAME significantly reduced the total number of $\mathrm{VPB}_{\min }$ from $30 \pm 9$ to $9 \pm 7$ (Figure 4). Both drugs reduced the incidence of ST-segment shift and the mortality rate was reduced to zero in both groups. When

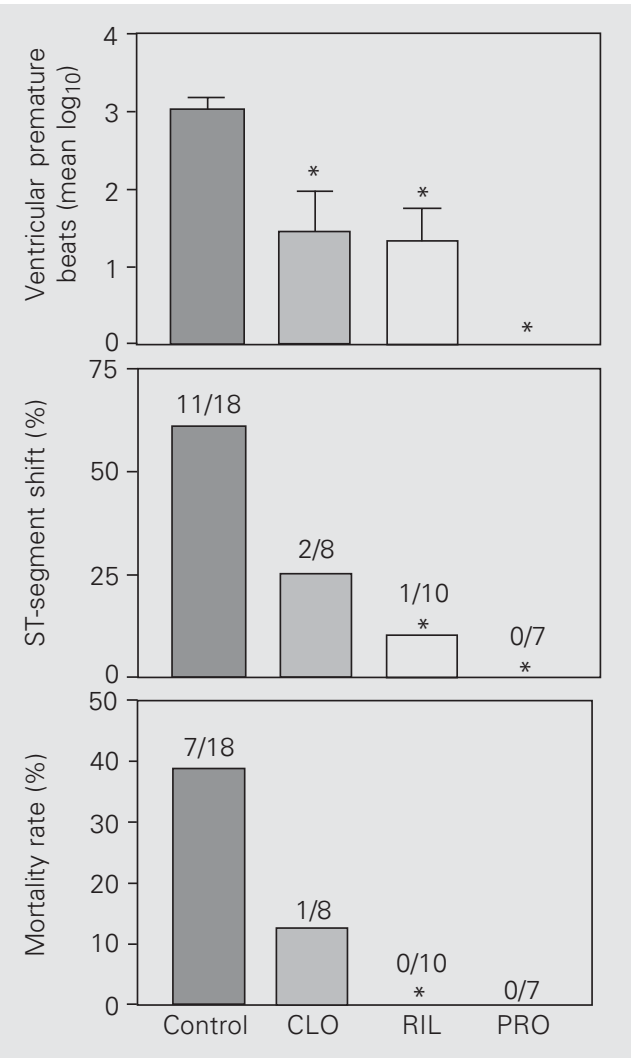

Figure 3. Effect of intravenous (iv) pretreatment with clonidine (CLO, $10 \mu \mathrm{g} / \mathrm{kg}$ ), rilmenidine (RIL, $300 \mu \mathrm{g} / \mathrm{kg}$ ) or propranolol (PRO, $500 \mu \mathrm{g} / \mathrm{kg}$ ) on ventricular arrhythmia, ECG ischemic changes and mortality rate observed after L-glutamate (10 $\mu \mathrm{mol}, i c v)$ in L-NAME $(40 \mathrm{mg} / \mathrm{kg}$, iv)-treated pentobarbital-anesthetized rabbits. Ventricular premature beats are reported as $\log _{10}$ values (see Methods). Data are reported as means and the vertical bars show the SEM. ${ }^{*} \mathrm{P}<0.05$ vs control group (Student-NewmanKeuls or Fisher exact test).

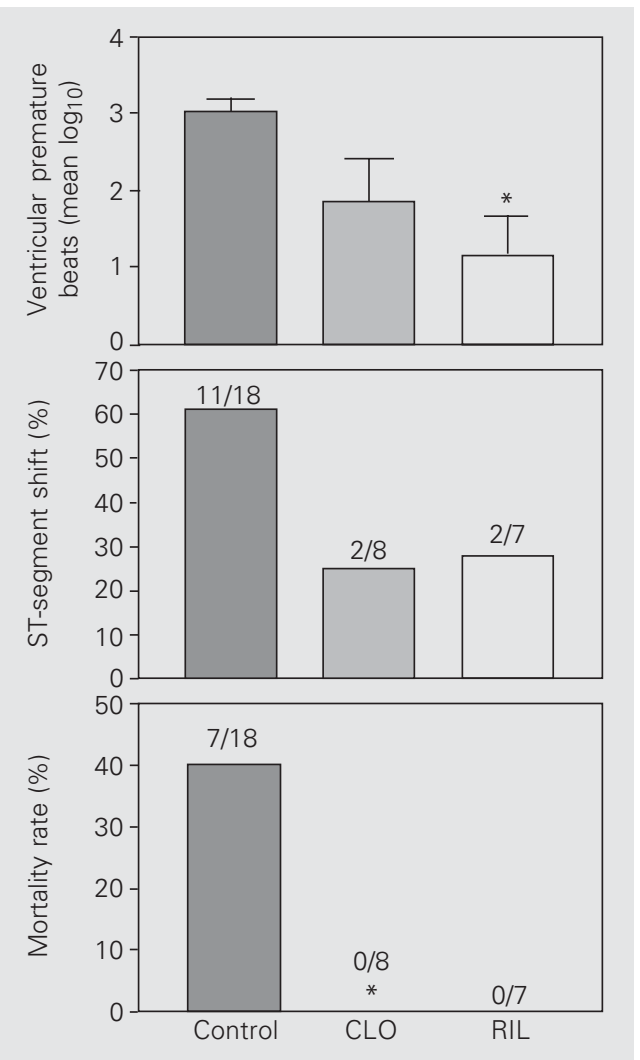

Figure 4. Effect of intracisternal pretreatment with clonidine (CLO, $1 \mu \mathrm{g} / \mathrm{kg}$ ) and rilmenidine (RIL, $30 \mu \mathrm{g} / \mathrm{kg}$ ) on ventricular arrhythmia, ECG ischemic changes and mortality rate observed after L-glutamate $(10 \mu \mathrm{mol})$ in LNAME $(40 \mathrm{mg} / \mathrm{kg}$, iv)-treated pentobarbital-anesthetized rabbits. The results are represented as in Figure 3. ${ }^{*} \mathrm{P}<0.05$ vs control group (Student-Newman-Keuls or Fisher exact test). 
Figure 5. Effect of intracisternal post-treatment with clonidine (CLO, $1 \mu \mathrm{g} / \mathrm{kg}$ ) and rilmenidine (RIL 3, $3 \mu \mathrm{g} / \mathrm{kg}$ and RIL 30, 30 $\mu \mathrm{g} / \mathrm{kg}$ ) on ventricular arrhythmia, ECG ischemic changes and mortality rate observed after L-glutamate $(10 \mu \mathrm{mol}, i c v)$ in L-NAME $(40 \mathrm{mg} / \mathrm{kg}, i \mathrm{i})$-treated pentobarbital-anesthetized rabbits. The results are represented as in Figure 3. ${ }^{*} \mathrm{P}<0.05$ vs control group (Student-Newman-Keuls or Fisher exact test).
Figure 6. Effect of the different systemic and central treatments with clonidine, rilmenidine and propranolol (treated) on mortality rate and incidence of ST-segment shift after central sympathetic stimulation with L-glutamate $(10 \mu \mathrm{mol}, i c v)$ in L-NAME (40 mg/kg, iv)-treated pentobarbital-anesthetized rabbits (control). ${ }^{*} P<0.05$ vs control group (Fisher exact test). clonidine $(1 \mu \mathrm{g} / \mathrm{kg}$ ) or rilmenidine (3 or 30 $\mu \mathrm{g} / \mathrm{kg}$ ) was injected ic $1 \mathrm{~h}$ after L-NAME administration the total number of $\mathrm{VPB}_{\text {min }}$ was significantly reduced from $30 \pm 9$ to $7 \pm$ $3,2 \pm 2$ and $6 \pm 3$, respectively (Figure 5).
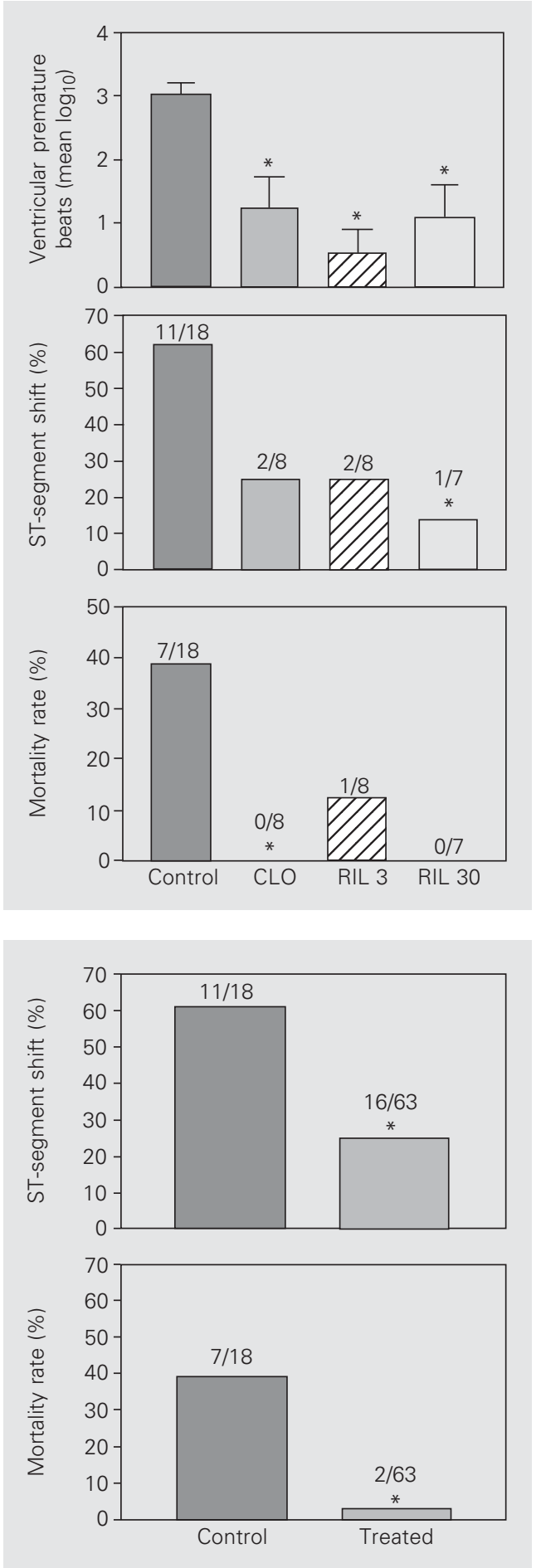

The mortality rate was markedly reduced by these treatments to $12.5 \%(1 / 8)$ in the group of animals pretreated with rilmenidine $(3 \mu \mathrm{g} /$ $\mathrm{kg})$ and all animals pretreated with rilmenidine $(30 \mu \mathrm{g} / \mathrm{kg})$ and clonidine $(1 \mu \mathrm{g} / \mathrm{kg})$ survived up to $30 \mathrm{~min}$ after L-glutamate injection. As was the case for the pretreated groups of animals, the incidence of ST-segment shift was also reduced.

Analysis of overall mortality in all treated groups, regardless of whether they had been treated by the systemic or central route, showed a marked increase of survival rate in comparison to untreated animals (Figure 6).

\section{Discussion}

The main finding of the present study was that clonidine and rilmenidine, two centrally acting antihypertensive drugs (see Introduction), reduce the incidence of ventricular tachyarrhythmia and death in anesthetized rabbits experiencing myocardial ischemia during increased central sympathetic activity. It is noteworthy that the cardioprotective effects of rilmenidine can also be obtained with very low doses of the drug, with no significant hypotensive effect. The term cardioprotection is used throughout this paper in order to depict the beneficial effects of pharmacological approaches in the primary and/or secondary prevention of myocardial ischemia, cardiac electrical instability and sudden death. In fact, an updated definition of cardioprotection should include the beneficial effects of any pharmacological agent used to preserve the heart by preventing myocardial damage (17).

The clinical use of clonidine for the protection of the ischemic heart during surgery has been well established $(18,19)$. Several clinical trials have shown that clonidine induces hemodynamic stability and reduces plasma catecholamine levels and myocardial oxygen demand in patients undergoing coronary artery bypass grafting, resulting in a decreased incidence of perioperative myo- 
cardial ischemia (20). This cardioprotective action of clonidine is clearly the result of the blockade of sympathetic overactivity induced by surgical stress. Thus, besides their antihypertensive properties, clonidine-like drugs present protective actions against cardiac events induced by sympathetic overactivity and can potentially be useful in the protection of patients with ischemic heart disease. Recent experimental evidence suggests that, in addition to their antihypertensive effect of central origin, second-generation sympathomodulatory agents such as rilmenidine also present antiarrhythmic properties (9). In fact, rilmenidine was able to blunt centrally induced ventricular arrhythmias through the inhibition of sympathetic hyperactivity in an experimental model of pharmacological activation of the central nervous system with bicuculline in anesthetized rabbits (21). Moreover, rilmenidine dose-dependently inhibits adrenaline-induced arrhythmias under halothane anesthesia in dogs, acting on central imidazoline receptors (22). These investigators suggested that the antiarrhythmic properties of rilmenidine in this particular experimental model result, at least in part, from simultaneous increases in vagal tone and baroreceptor sensitivity (22). Using an identical experimental model, Hayashi et al. (23) demonstrated that the arrhythmogenic dose of adrenaline decreases in a dose-dependent manner only after treatment with $\alpha_{2}$-adrenoceptor antagonists with an imidazoline structure but not with non-imidazoline antagonists such as yohimbine. Similar results were reported by Poisson et al. (24), using iv moxonidine, in a model of neurogenic arrhythmias induced by electrical stimulation of the posterior hypothalamus in anesthetized rabbits.

In the present study, we used an experimental model of sympathetic overactivity in L-NAME-treated and anesthetized rabbits, relevant for the pre-clinical investigation of antiarrhythmic drugs in the prevention of life-threatening ventricular tachyarrhythmias.
In fact, loss of autonomic balance characterized by increased sympathetic activity and decreased vagal activity is among the major cardiovascular risk factors (6). We have shown previously that the pharmacological stimulation of the central nervous system with L-glutamate injected into the lateral ventricle of rabbits markedly increases the sympathetic outflow to the periphery, resulting in important increases in myocardial oxygen consumption $(8,25)$. It is noteworthy that successive stimulations are not possible in this experimental model since repeated injections of L-glutamate in the same animal lead to tachyphylaxis. Myocardial ischemia was induced by central nervous system activation with L-glutamate in L-NAME-treated rabbits. L-NAME is an analogue of L-arginine, which is known to competitively inhibit the enzyme nitric oxide synthase (26). It has been shown that acute blockade of the Larginine-nitric oxide pathway induces systemic (27) as well as coronary vasoconstriction $(28,29)$. Under our experimental conditions, the systemic treatment of anesthetized rabbits with a dose of $40 \mathrm{mg} / \mathrm{kg}$ L-NAME did not induce marked increases in arterial pressure or ischemic alterations of the ECG. Moreover, in spite of the important increases in cardiovascular parameters and myocardial oxygen consumption, L-glutamate alone did not evoke myocardial ischemia, demonstrating that the ECG changes observed in the L-NAME/L-glutamate-treated animals did not result from L-glutamate-induced increases in left ventricular afterload. On the other hand, ventricular arrhythmia, myocardial ischemia and death were observed immediately after activation of the central nervous system with L-glutamate in animals pretreated with L-NAME, proving sympathetic overactivity associated with a reduction of coronary blood flow to be highly deleterious to the heart. In the experimental protocol used in the present study, which did not include histopathological evaluation of the heart, the distinction between a transi- 
tory ischemic effect and overt myocardial infarction was not possible. Nevertheless, the results of our study showed that the incidence of ventricular arrhythmia and myocardial ischemia as well as the mortality rate were markedly reduced or even completely abolished in animals systemically treated with hypotensive doses of clonidine $(10 \mu \mathrm{g} /$ $\mathrm{kg})$ or rilmenidine $(300 \mu \mathrm{g} / \mathrm{kg})$. A similar cardioprotective effect was obtained with the $i c$ injection of ten times lower doses of clonidine or rilmenidine, suggesting that this effect can be explained by a modulatory action on the central control of the sympathetic drive. In fact, clonidine and rilmenidine are known to inhibit the activity of sympathoexcitatory neurons in the ventrolateral medulla acting on $\alpha_{2}$-adrenoceptors and imidazoline receptors $(11,12,30)$, resulting in a reduction of the activity of sympathetic preganglionic neurons. Treatment with ic clonidine $(1 \mu \mathrm{g} / \mathrm{kg}$ ) but not rilmenidine (3 or $30 \mu \mathrm{g} / \mathrm{kg}$ ) was more effective when performed immediately before L-glutamate, probably because rilmenidine induces a longer-lasting effect after central administration. Interestingly, the central administration of low doses of rilmenidine $(3 \mu \mathrm{g} / \mathrm{kg})$, which did not induce arterial hypotension or cardiac depression, also elicited a cardioprotective effect in our experimental model. Thus, these results indicate a dissociation of the antiarrhythmic and antihypertensive prop- erties of sympathomodulatory agents such as rilmenidine.

It has been well established from several large clinical trials that a ß-blocker treatment of patients after myocardial infarction reduces the incidence of ventricular arrhythmia and the mortality rate (7). This cardioprotective action of $\beta$-blockers has mainly been attributed to a bradycardic effect associated with a beneficial influence of the drug on the autonomic control of heart rate, namely an inhibition on cardiac sympathetic drive (31). Furthermore, the main site of the central cardiovascular actions of clonidine and rilmenidine, namely the reticulospinal vasomotor neurons of the rostral ventrolateral medulla (9), which contribute significantly to the maintenance of tonic sympathetic vasomotor activity, is also involved in the central hypotensive effects of propranolol (32). Thus, it is reasonable to conclude that the cardioprotective effects of propranolol, at least under our experimental conditions, are partly due to its effects on the central nervous system. Finally, it is noteworthy that the blockade of $\beta$-adrenergic receptors induces important reductions of cardiac contractility, at least in experimental models of myocardial ischemia (3). This was not the case for the treatment with subhypotensive doses of rilmenidine (present study), which did not present any cardiodepressive effect while still eliciting a cardioprotective effect.

\section{References}

1. Brook RD \& Julius S (2000). Autonomic imbalance, hypertension, and cardiovascular risk. American Journal of Hypertension, 13 (Part 2): $112 \mathrm{~S}-122 \mathrm{~S}$

2. Davis AM \& Natelson BJ (1993). Brain-heart interactions. The neurocardiology of arrhythmia and sudden cardiac death. Texas Heart Institute Journal, 20: 158-169.

3. De Ferrari GM, Salvati P, Grossoni M, Ukmar G, Vaga L, Patrono C \& Schwartz PJ (1993). Pharmacologic modulation of the autonomic nervous system in the prevention of sudden cardiac death. A study with propranolol, methacholine and oxotremorine in conscious dogs with a healed myocardial infarction. Journal of the American College of Cardiology, 22: 283-290

4. Lown B, Verrier RL \& Rabinowitz MD (1977). Neural and psychological mechanisms and the problem of sudden cardiac death. American
Journal of Cardiology, 39: 890-902.

5. Billman GE, Schwartz PJ \& Stone HL (1982). Baroreceptor reflex control of heart rate: a predictor of sudden cardiac death. Circulation, 66: 874-880.

6. Vanoli E \& Schwartz PJ (1990). Sympathetic-parasympathetic interaction and sudden death. Basic Research in Cardiology, 85 (Suppl 1): 305-321.

7. Hjalmarson A (1999). Prevention of sudden cardiac death with beta blockers. Clinical Cardiology, 22 (Suppl 5): V11-V15.

8. Grabe-Guimarães A, Alves LM, Tibiriça E \& Nobrega AC (1999). Pyridostigmine blunts the increases in myocardial oxygen demand elicited by the stimulation of the central nervous system in anesthetized rats. Clinical Autonomic Research, 9: 83-89.

9. Bousquet P \& Feldman J (1999). Drugs acting on imidazoline recep- 
tors: a review of their pharmacology, their use in blood pressure control and their potential interest in cardioprotection. Drugs, 58: 799-812.

10. Bousquet P, Feldman J \& Schwartz J (1984). Central cardiovascular effects of alpha-adrenergic drugs: difference between catecholamines and imidazolines. Journal of Pharmacology and Experimental Therapeutics, 230: 232-236.

11. Tibiriçá E, Feldman J, Mermet C, Monassier L, Gonon F \& Bousquet $P$ (1991). Selectivity of rilmenidine for the nucleus reticularis lateralis, a ventrolateral medullary structure containing imidazoline-preferring receptors. European Journal of Pharmacology, 209: 213-221.

12. Tibiriçá E, Feldman J, Mermet C, Gonon F \& Bousquet P (1991). An imidazoline-specific mechanism for the hypotensive effect of clonidine: a study with yohimbine and idazoxan. Journal of Pharmacology and Experimental Therapeutics, 256: 606-613.

13. Chan CK, Sannajust F \& Head GA (1996). Role of imidazoline receptors in the cardiovascular actions of moxonidine, rilmenidine and clonidine in conscious rabbits. Journal of Pharmacology and Experimental Therapeutics, 276: 411-420.

14. De Sarro GB, Ascioti C, Froio F, Libri V \& Nistico G (1987). Evidence that locus coeruleus is the site where clonidine and drugs acting at alpha1- and alpha2-adrenoceptors affect sleep and arousal mechanisms. British Journal of Pharmacology, 90: 675-685.

15. Hjalmarson A (1997). Effects of beta blockade on sudden cardiac death during acute myocardial infarction and the postinfarction period. Journal of Cardiology, 80: 35J-39J.

16. Sawyer CH, Everett JW \& Green JD (1954). The rabbit diencephalon in stereotaxic coordinates. Journal of Comparative Neurology, 101: 801-824.

17. Kübler W \& Haass M (1996). Cardioprotection: definition, classification, and fundamental principles. Heart, 75: 330-333.

18. Hayashi $Y$ \& Maze M (1993). Alpha 2 adrenoceptor agonists and anaesthesia. British Journal of Anaesthesia, 71: 108-118.

19. Fulgencio JP, Rimaniol JM, Catoire P \& Bonnet F (1994). Clonidine and postoperative myocardial ischemia. Canadian Journal of Anaesthesia, 41: 550-551.

20. Dorman BH, Zucker JR, Verrier ED, Gartman DM \& Slachman FN (1993). Clonidine improves perioperative myocardial ischemia, reduces anesthetic requirement, and alters hemodynamic parameters in patients undergoing coronary artery bypass surgery. Journal of Cardiothoracic and Vascular Anesthesia, 7: 386-395.

21. Roegel JC, Yannoulis N, De Jong W, Monassier L, Feldman J \& Bousquet $P$ (1996). Inhibition of centrally induced ventricular arrhythmias by rilmenidine and idazoxan in rabbits. Naunyn-Schmiedeberg's Archives of Pharmacology, 354: 598-605.
22. Mammoto $T$, Kamibayashi $T$, Hayashi $Y$, Yamatodani $A$, Takada $K$ \& Yoshiya I (1996). Antiarrhythmic action of rilmenidine on adrenalineinduced arrhythmia via central imidazoline receptors in halothaneanaesthetized dogs. British Journal of Pharmacology, 117: 17441748 .

23. Hayashi Y, Kamibayashi T, Maze M, Yamatodani A, Sumikawa K, Kuro M \& Yoshiya I (1993). Role of imidazoline-preferring receptors in the genesis of epinephrine-induced arrhythmias in halothaneanesthetized dogs. Anesthesiology, 78: 524-530.

24. Poisson D, Christen MO \& Sannajust F (2000). Protective effects of I(1)-antihypertensive agent moxonidine against neurogenic cardiac arrhythmias in halothane-anesthetized rabbits. Journal of Pharmacology and Experimental Therapeutics, 293: 929-938.

25. Tibiriçá E, Catelli M, Lessa MA, Roegel JC, Feldman J, Monassier L \& Bousquet $P$ (1995). Inhibition of the centrally-induced increases in myocardial oxygen demand in rabbits by chronic treatment with

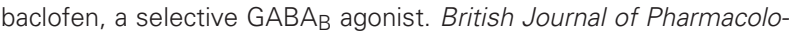
gy, 115: 1331-1335.

26. Hobbs AJ, Higgs A \& Moncada S (1999). Inhibition of nitric oxide synthase as a potential therapeutic target. Annual Review of Pharmacology and Toxicology, 39: 191-220.

27. Gardiner SM, Kemp PA, Bennett T, Palmer RM \& Moncada S (1993). Regional and cardiac haemodynamic effects of NG-dimethyl-L-arginine and their reversibility by vasodilators in conscious rats. British Journal of Pharmacology, 110: 1457-1464.

28. Humphries RG, Carr RD, Nicol AK, Tomlinson W \& O'Connor SE (1991). Coronary vasoconstriction in the conscious rabbit following intravenous infusion of L-NG-nitro-arginine. British Journal of Pharmacology, 102: 565-566.

29. Pomposiello S, Yang XP, Liu YH, Surakanti M, Rhaleb NE, Sevilla M \& Carretero AO (1997). Autacoids mediate coronary vasoconstriction induced by nitric oxide synthesis inhibition. Journal of Cardiovascular Pharmacology, 30: 599-606.

30. Gomez RE, Ernsberger P, Feinland G \& Reis DJ (1991). Rilmenidine lowers arterial pressure via imidazole receptors in brainstem $\mathrm{C} 1$ area. European Journal of Pharmacology, 195: 181-191.

31. Schweizer MW, Brachmann J, Kirchner U, Walter-Sack I, Dickhaus H, Metze C \& Kubler W (1993). Heart rate variability in time and frequency domains: effects of gallopamil, nifedipine, and metoprolol compared with placebo. British Heart Journal, 70: 252-258.

32. Privitera PJ, Webb JG \& Walle T (1979). C1 area of the rostral ventrolateral medulla as a site for the central hypotensive action of propranolol. Journal of Pharmacology and Experimental Therapeutics, 246: 529-533. 